Supporting Information for

\title{
Structure-Stability Relationship of Amorphous
}

\section{$\mathrm{IrO}_{2}-\mathrm{Ta}_{2} \mathrm{O}_{5}$ Electrocatalysts on a Ti Felt for}

\section{Oxygen Evolution in Sulfuric Acid}

Fumiaki Amano, ${ }^{a, b,{ }^{*}}$ Yoshiyuki Furusho, ${ }^{a}$ Seiji Yamazoe, ${ }^{b, c}$ and Muneaki Yamamoto ${ }^{d}$

${ }^{a}$ Department of Chemical and Environmental Engineering, The University of Kitakyushu, 1-1 Hibikino, Wakamatsu, Kitakyushu, Fukuoka 808-0135, Japan.

${ }^{b}$ Precursory Research for Embryonic Science and Technology (PRESTO), Japan Science and Technology Agency (JST), 4-1-8 Honcho, Kawaguchi, Saitama 332-0012, Japan.

${ }^{c}$ Department of Chemistry, Graduate School of Science, Tokyo Metropolitan University, 1-1 Hachioji-shi, Tokyo 192-0397, Japan

${ }^{d}$ Research Center for Artificial Photosynthesis, Osaka City University, 3-3-138 Sugimoto, Osaka 558-8585, Japan.

*Corresponding Author, E-mail Address: amano@ kitakyu-u.ac.jp

ORCID ID, Fumiaki Amano: 0000-0003-2812-5799, Seiji Yamazoe: 0000-0002-8382-8078 
Table S1. Conditions for extracting structural parameters in Ir $\mathrm{L}_{3}$-edge EXAFS curve fitting. ${ }^{a}$

\begin{tabular}{ccccc}
\hline Standard sample & Shell & $\mathbf{C N}$ & $\boldsymbol{r} / \AA$ & $\mathbf{D W} / \AA$ \\
\hline \hline $\mathrm{IrO}_{2}$ & $\mathrm{Ir}-\mathrm{O}$ & 6.0 & 1.99 & 0.060 \\
\hline & $\mathrm{Ir}-(\mathrm{O})-\mathrm{Ir}$ & 2.0 & 3.16 & 0.060 \\
\hline$\left(\mathrm{NH}_{4}\right)_{2} \mathrm{IrCl}_{6}$ & $\mathrm{Ir}-\mathrm{Cl}$ & 6.0 & 2.47 & 0.060 \\
\hline Ir metal with BN & $\mathrm{Ir}-\mathrm{Ir}$ & 12.0 & 2.74 & 0.060 \\
\hline
\end{tabular}

${ }^{a} \mathrm{CN}$ is the coordination number, $r$ is the bond length, and DW is the Debye-Waller factor. The phase shifts and backscattering amplitude functions of $\mathrm{Ir}-\mathrm{O}, \mathrm{Ir}-(\mathrm{O})-\mathrm{Ir}, \mathrm{Ir}-\mathrm{Cl}$, and $\mathrm{Ir}-\mathrm{Ir}$ were extracted from the FT-EXAFS spectra of $\mathrm{IrO}_{2},\left(\mathrm{NH}_{4}\right)_{2} \mathrm{IrCl}_{6}$, and Ir metal. The FT-EXAFS spectrum was obtained by Fourier transformation of the EXAFS oscillation in a $k$ range of 3.0-10.5 $\AA^{-1}$. The Ir-O bond length was the value taken from the average of four Ir-O bonds with $1.9988(9)$ $\AA$ and two bonds with 1.9604(14) $\AA$. The Ir- $-(\mathrm{O})-$ Ir bonds were taken from the second coordination sphere (J. Phys. Chem. B, 1998, 102, 3736-3741). 
Table S2. TG-DTA results of the precursor components. ${ }^{a}$

\begin{tabular}{lccc}
\hline Sample & $\begin{array}{c}\text { Measured value } \\
{[\%]}\end{array}$ & $\begin{array}{c}\text { Theoretical value } \\
{[\%]^{a}}\end{array}$ & Assumed residue \\
\hline \hline $\mathrm{H}_{2} \mathrm{IrCl}_{6}$ & 46.2 & 44.9 & $\mathrm{IrO}_{2}$ \\
\hline $\mathrm{TaCl}_{5}$ & 37.5 & 38.3 & $\mathrm{Ta}_{2} \mathrm{O}_{5}$ \\
\hline $\mathrm{H}_{2} \mathrm{IrCl}_{6}-\mathrm{TaCl}_{5}$ & 38.4 & 43.1 & $\mathrm{IrO}_{2}-\mathrm{Ta}_{2} \mathrm{O}_{5}$ \\
\hline $\mathrm{PEG}$ & 100 & 100 & none $^{b}$ \\
\hline $\mathrm{H}_{2} \mathrm{IrCl}_{6}-\mathrm{TaCl}_{5}$ with PEG & 78.2 & 75.0 & $\mathrm{IrO}_{2}-\mathrm{Ta}_{2} \mathrm{O}_{5}$ \\
\hline
\end{tabular}

${ }^{a}$ The theoretical values were calculated assuming the residue.

${ }^{b}$ PEG is thermally decomposed into carbon dioxide and water vapor in the air.

Table S3. X-ray fluorescence (XRF) elemental analysis of $\mathrm{IrO}_{2}-\mathrm{Ta}_{2} \mathrm{O}_{5}$ powders prepared in evaporating dish.

\begin{tabular}{lcccc}
\hline Sample & Ir [mol \%] & Ta [mol \%] & Cl [mol \%] & Ir : Ta \\
\hline \hline $\mathrm{P}(350)$ & 55.4 & 28.5 & 16.1 & $64.7: 35.3$ \\
\hline $\mathrm{P}(350)-\mathrm{PEG}$ & 64.4 & 33.9 & 1.63 & $64.1: 35.9$ \\
\hline $\mathrm{P}(550)$ & 64.7 & 34.0 & 1.29 & $64.2: 35.8$ \\
\hline $\mathrm{P}(550)-\mathrm{PEG}$ & 66.9 & 32.7 & 0.42 & $65.8: 34.2$ \\
\hline
\end{tabular}


Table S4. SEM-EDS elemental analysis of $\mathrm{IrO}_{2}-\mathrm{Ta}_{2} \mathrm{O}_{5}$ powders prepared in evaporating dish.

\begin{tabular}{lccccc}
\hline Sample & Ir [mol \%] & Ta [mol \%] & Cl [mol \%] & O [mol \%] & Ir : Ta \\
\hline \hline $\mathrm{P}(350)$ & 12.9 & 7.03 & 31.6 & 48.4 & $63.3: 36.7$ \\
\hline $\mathrm{P}(350)-\mathrm{PEG}$ & 11.4 & 8.72 & 2.41 & 77.4 & $55.2: 44.8$ \\
\hline $\mathrm{P}(550)$ & 20.9 & 12.1 & 3.54 & 63.4 & $61.8: 38.2$ \\
\hline $\mathrm{P}(550)-\mathrm{PEG}$ & 22.7 & 14.8 & 0.88 & 61.6 & $59.1: 40.9$ \\
\hline
\end{tabular}


Table S5. Tafel analysis for the cyclic voltammograms of $\mathrm{IrO}_{2}-\mathrm{Ta}_{2} \mathrm{O}_{5} / \mathrm{Ti}$ felt(y)-PEG in $0.1 \mathrm{M}$ $\mathrm{H}_{2} \mathrm{SO}_{4}$ aqueous solution $(\mathrm{pH}=1)$ with a scan rate of $20 \mathrm{mV} \mathrm{s}^{-1}$. The current density $(j)$ at $1.43 \mathrm{~V}$ vs. RHE was estimated from the Tafel plot.

\begin{tabular}{|c|c|c|c|c|}
\hline Sample & $\begin{array}{l}\text { Tafel slope } \\
{\left[\mathrm{mV} \mathrm{dec}^{-1}\right]}\end{array}$ & 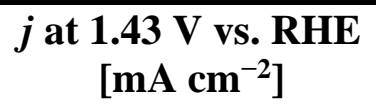 & $\begin{array}{c}C_{\mathbf{d l}} \\
{\left[\mathrm{mF} \mathrm{cm}^{-2}\right]^{a}}\end{array}$ & $\begin{array}{c}\text { ECSA } \\
{\left[\mathrm{cm}^{2}\right]^{b}}\end{array}$ \\
\hline felt(250)-PEG & 160 & 1.31 & 14.7 & 420 \\
\hline felt(300)-PEG & 69.7 & 1.45 & 113.6 & 3246 \\
\hline felt(350)-PEG & 41.2 & 0.92 & 102.8 & 2938 \\
\hline felt(400)-PEG & 49.9 & 0.21 & 63.8 & 1823 \\
\hline felt(450)-PEG & 56.9 & 0.13 & 32.5 & 929 \\
\hline felt(550)-PEG & 60.7 & 0.05 & 22.7 & 649 \\
\hline felt(650)-PEG & 73.7 & 0.02 & 12.6 & 361 \\
\hline
\end{tabular}

${ }^{a}$ Double-layer capacitance $\left(C_{\mathrm{dl}}\right)$ estimated from the voltammogram at $0.50 \mathrm{~V}$ vs. RHE.

${ }^{b}$ Electrochemical surface area (ECSA) calculated from the $C_{\mathrm{dl}}$ assuming that the specific capacitance of atomically flat surface is $0.035 \mathrm{mF} \mathrm{cm}^{-2}$ in $1 \mathrm{M} \mathrm{H}_{2} \mathrm{SO}_{4}$. 
Table S6. Potential increase of $\mathrm{IrO}_{2}-\mathrm{Ta}_{2} \mathrm{O}_{5}$ electrodes during OER measurement at $50 \mathrm{~mA} \mathrm{~cm}{ }^{-2}$ for $4 \mathrm{~h}$.

\begin{tabular}{lccc}
\hline \multicolumn{1}{c}{ Sample } & $\begin{array}{c}\text { Potential at } \mathbf{~ h} \\
{[\mathbf{V}]}\end{array}$ & $\begin{array}{c}\text { Potential at } \mathbf{4 h} \\
{[\mathbf{V}]}\end{array}$ & $\begin{array}{c}\mathbf{d} \boldsymbol{\mathbf { h }} / \mathbf{d} t \\
{\left[\mathbf{m V ~ h} \mathbf{~ h}^{-1}\right]^{a}}\end{array}$ \\
\hline \hline felt(350) & 1.558 & 1.635 & 6.78 \\
\hline felt(350)-PEG & 1.518 & 1.557 & 2.99 \\
\hline felt(550) & 1.669 & 1.775 & 4.79 \\
\hline felt(550)-PEG & 1.670 & 1.766 & 5.24 \\
\hline plate(350) & 1.629 & 2.401 & 147.2 \\
\hline plate(350)-PEG & 1.598 & 1.651 & 3.60 \\
\hline
\end{tabular}

${ }^{a}$ Slope of the fitting line for the potential increase from $1 \mathrm{~h}$ to $4 \mathrm{~h}$ in the chronopotentiometry measurement. The fitting for $\mathrm{IrO}_{2}-\mathrm{Ta}_{2} \mathrm{O}_{5} / \mathrm{Ti}$ plate(350) was performed from $1 \mathrm{~h}$ to $3 \mathrm{~h}$. 
Table S7. ICP-OES analysis of the electrolyte after OER measurement of $\mathrm{IrO}_{2}-\mathrm{Ta}_{2} \mathrm{O}_{5}$ electrodes at $50 \mathrm{~mA} \mathrm{~cm}^{-2}$ for $4 \mathrm{~h}$.

\begin{tabular}{lccc}
\hline \multicolumn{1}{c}{ Sample } & $\begin{array}{c}\text { Concentration of Ir } \\
{[\mathbf{p p m}]}\end{array}$ & $\begin{array}{c}\text { Dissolution of Ir }^{b} \\
{[\%]}\end{array}$ & $\begin{array}{c}\text { Stability number }^{c} \\
{\left[\boldsymbol{n}\left(\mathbf{O}_{2}\right) / \boldsymbol{n}(\mathbf{I r})\right]}\end{array}$ \\
\hline \hline felt(350) & 0.423 & 5.24 & $1.70 \times 10^{4}$ \\
\hline felt(350)-PEG & 0.0453 & 0.54 & $1.58 \times 10^{5}$ \\
\hline felt(550) & 0.0290 & 0.36 & $2.47 \times 10^{5}$ \\
\hline felt(550)-PEG & 0.0110 & 0.13 & $6.52 \times 10^{5}$ \\
\hline plate(350) & 6.07 & 75.2 & $1.18 \times 10^{3}$ \\
\hline plate(350)-PEG & 0.0913 & 1.13 & $7.86 \times 10^{4}$ \\
\hline
\end{tabular}

${ }^{a}$ The Ir concentration in the 50-mL electrolyte solution analyzed by ICP-OES.

${ }^{b}$ The Ir dissolution calculated by considering the $\mathrm{Ir}$ mass $\left(0.4 \mathrm{mg} \mathrm{cm}^{-2}\right)$ in each $\operatorname{IrO}_{2}-\mathrm{Ta}_{2} \mathrm{O}_{5}(x) / \mathrm{Ti}$ felt.

${ }^{c}$ A dimensionless descriptor that compares the amount of $\mathrm{O}_{2}$ evolved, calculated from the measured current density at an estimated $100 \%$ current efficiency towards OER, with the amount of Ir dissolved. 
Table S8. ICP-OES analysis of the electrolyte after the stability test of $\mathrm{IrO}_{2}-\mathrm{Ta}_{2} \mathrm{O}_{5} / \mathrm{Ti}$ felt(350) electrodes at $20 \mathrm{~mA} \mathrm{~cm}^{-2}$ for $24 \mathrm{~h}$.

\begin{tabular}{lccc}
\hline \multicolumn{1}{c}{ Sample } & $\begin{array}{c}{\text { Concentration of } \text { Ir }^{a}}^{a} \\
{[\mathbf{p p m}]}\end{array}$ & $\begin{array}{c}\text { Dissolution of } \mathbf{I r}^{b} \\
{[\%]}\end{array}$ & $\begin{array}{c}\text { Stability number }^{c} \\
{\left[\boldsymbol{n}\left(\mathbf{O}_{2}\right) / \boldsymbol{n}(\mathbf{I r})\right]}\end{array}$ \\
\hline \hline felt(350) & 0.895 & 11.1 & $1.92 \times 10^{4}$ \\
\hline felt(350)-PEG & 0.224 & 2.77 & $7.68 \times 10^{4}$ \\
\hline
\end{tabular}

${ }^{a}$ The Ir concentration in the 50-mL electrolyte solution analyzed by ICP-OES.

${ }^{b}$ The Ir dissolution calculated by considering the Ir mass $\left(0.4 \mathrm{mg} \mathrm{cm}^{-2}\right)$ in each $\mathrm{IrO}_{2}-\mathrm{Ta}_{2} \mathrm{O}_{5} / \mathrm{Ti}$ felt sample.

${ }^{c}$ A dimensionless descriptor that compares the amount of $\mathrm{O}_{2}$ evolved, calculated from the measured current density at an estimated $100 \%$ current efficiency towards OER, with the amount of Ir dissolved.

Table S9. XRF elemental analysis of the $\mathrm{IrO}_{2}-\mathrm{Ta}_{2} \mathrm{O}_{5} / \mathrm{Ti}$ felt(350) electrodes before and after the stability test at $20 \mathrm{~mA} \mathrm{~cm}^{-2}$ for $24 \mathrm{~h}$.

\begin{tabular}{lcccc}
\hline Sample & Condition & Ir [mol \%] & Ta [mol \%] & Ti [mol \%] \\
\hline \hline felt(350) & as prepared & 1.81 & 1.82 & 96.3 \\
\hline & after reaction & 1.10 & 0.85 & 98.0 \\
\hline felt(350)-PEG & as prepared & 5.08 & 1.95 & 93.0 \\
\hline & after reaction & 4.41 & 1.68 & 93.9 \\
\hline
\end{tabular}


Table S10. XRF elemental analysis of $\mathrm{IrO}_{2}-\mathrm{Ta}_{2} \mathrm{O}_{5} / \mathrm{Ti}$ felt electrodes prepared with PEG and without PEG.

\begin{tabular}{cccccc}
\hline Sample & Ir [mol \%] & Ta [mol \%] & Ti [mol \%] & Cl [mol \%] & Ir : Ta \\
\hline \hline felt(250)-PEG & 1.88 & 0.853 & 97.1 & 0.136 & $67.5: 32.5$ \\
\hline felt(350)-PEG & 3.05 & 1.37 & 95.5 & 0.080 & $67.7: 32.3$ \\
\hline felt(450)-PEG & 2.51 & 1.09 & 96.4 & 0 & $68.4: 31.6$ \\
\hline felt(550)-PEG & 2.46 & 1.09 & 96.5 & 0 & $68.0: 32.0$ \\
\hline felt(650)-PEG & 2.41 & 1.05 & 96.5 & 0 & $68.4: 31.6$ \\
\hline
\end{tabular}

\begin{tabular}{cccccc}
\hline Sample & Ir [mol \%] & Ta [mol \%] & Ti [mol \%] & Cl [mol \%] & Ir : Ta \\
\hline \hline felt(250) & 0.783 & 0.341 & 98.7 & 0.151 & $68.4: 31.6$ \\
\hline felt(350) & 0.919 & 0.445 & 98.6 & 0.035 & $66.0: 34.0$ \\
\hline felt(450) & 0.740 & 0.312 & 98.9 & 0 & $69.1: 30.9$ \\
\hline felt(550) & 0.865 & 0.39 & 98.7 & 0 & $67.6: 32.4$ \\
\hline felt(650) & 2.34 & 1.29 & 96.4 & 0 & $63.1: 36.9$ \\
\hline
\end{tabular}



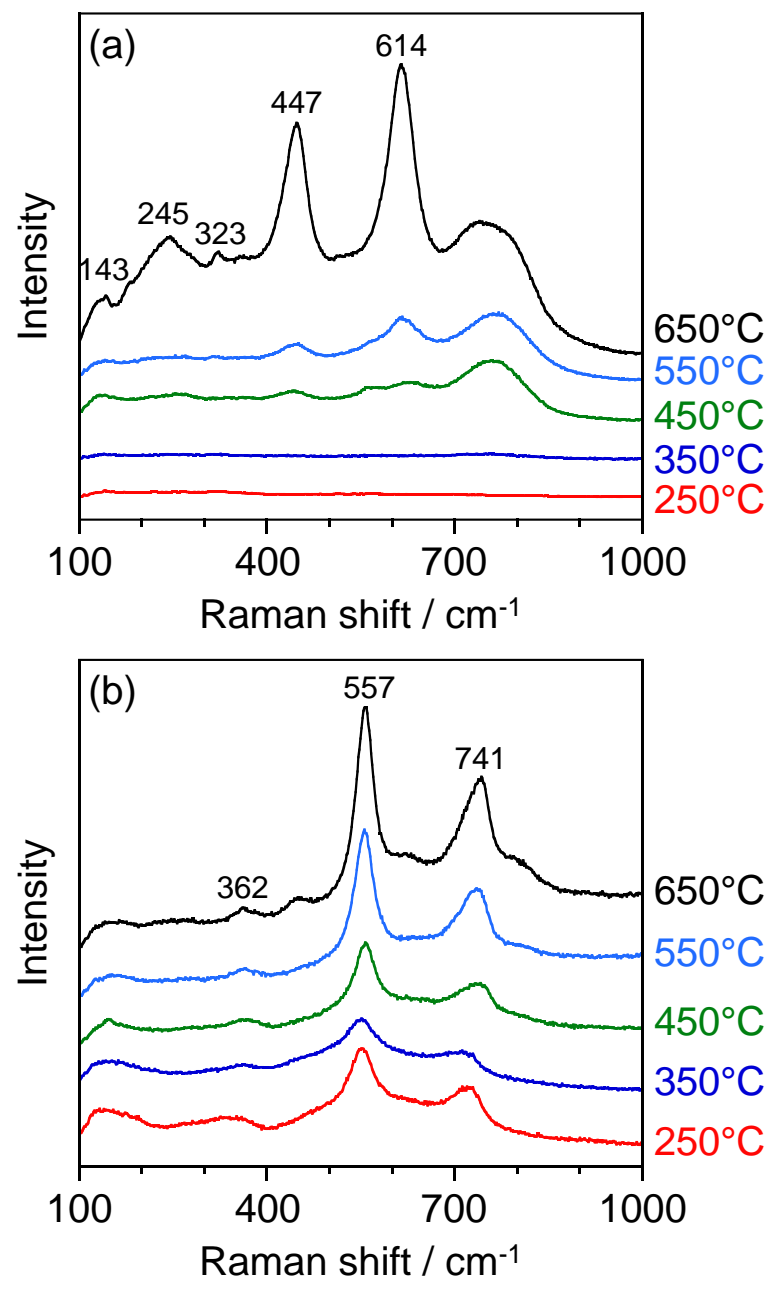

Figure S1. Raman spectra of the (a) $\mathrm{IrO}_{2}-\mathrm{Ta}_{2} \mathrm{O}_{5} / \mathrm{Ti}$ felt $(x)-\mathrm{PEG}$ and (b) $\mathrm{IrO}_{2}-\mathrm{Ta}_{2} \mathrm{O}_{5} / \mathrm{Ti}$ plate $(x)-$ PEG prepared by different calcination temperatures. 

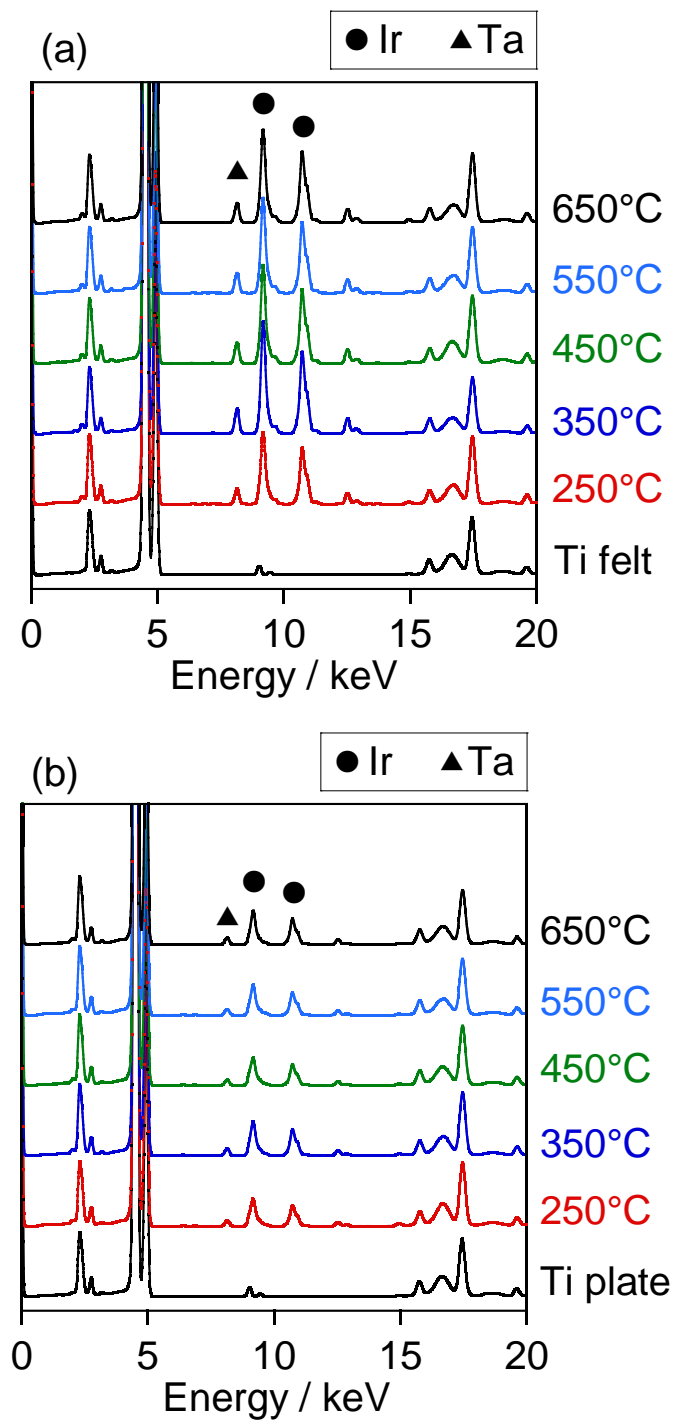

Figure S2. XRF spectra of (a) $\mathrm{IrO}_{2}-\mathrm{Ta}_{2} \mathrm{O}_{5} / \mathrm{Ti}$ felt $(x)-\mathrm{PEG}$ and (b) $\mathrm{IrO}_{2}-\mathrm{Ta}_{2} \mathrm{O}_{5} / \mathrm{Ti}$ plate $(x)-\mathrm{PEG}$ prepared by different calcination temperatures. The spectra were obtained with Mo secondary target. 

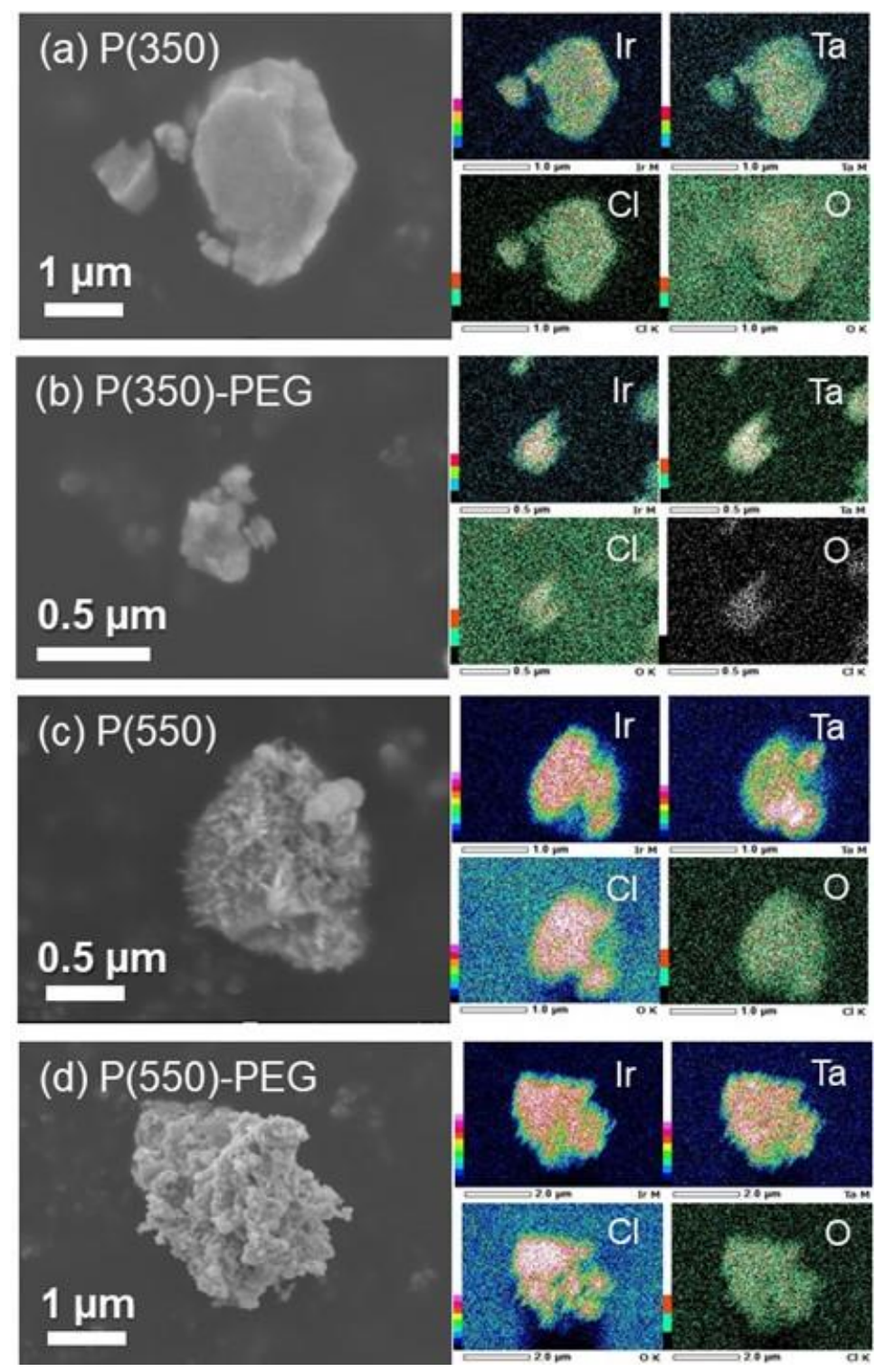

Figure S3. SEM and EDS images of IrO2-Ta2O5 powders: (a) P(350), (b) P(350)-PEG, (c) $\mathrm{P}(550)$, and (d) P(550)-PEG. 

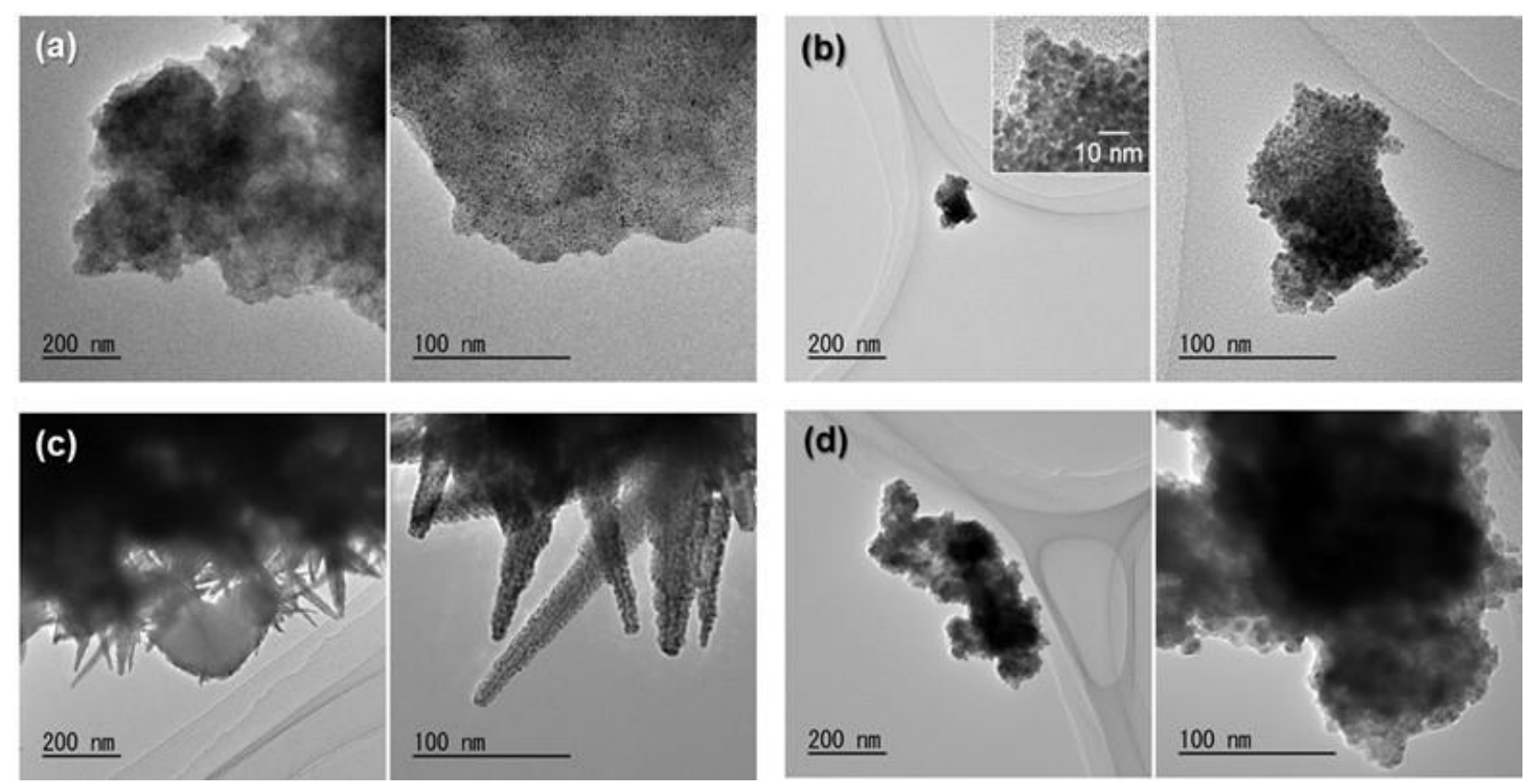

Figure S4. TEM images of $\mathrm{IrO}_{2}-\mathrm{Ta}_{2} \mathrm{O}_{5}$ powders: (a) $\mathrm{P}(350)$, (b) $\mathrm{P}(350)-\mathrm{PEG}$, (c) $\mathrm{P}(550)$, and (d) P(550)-PEG. 

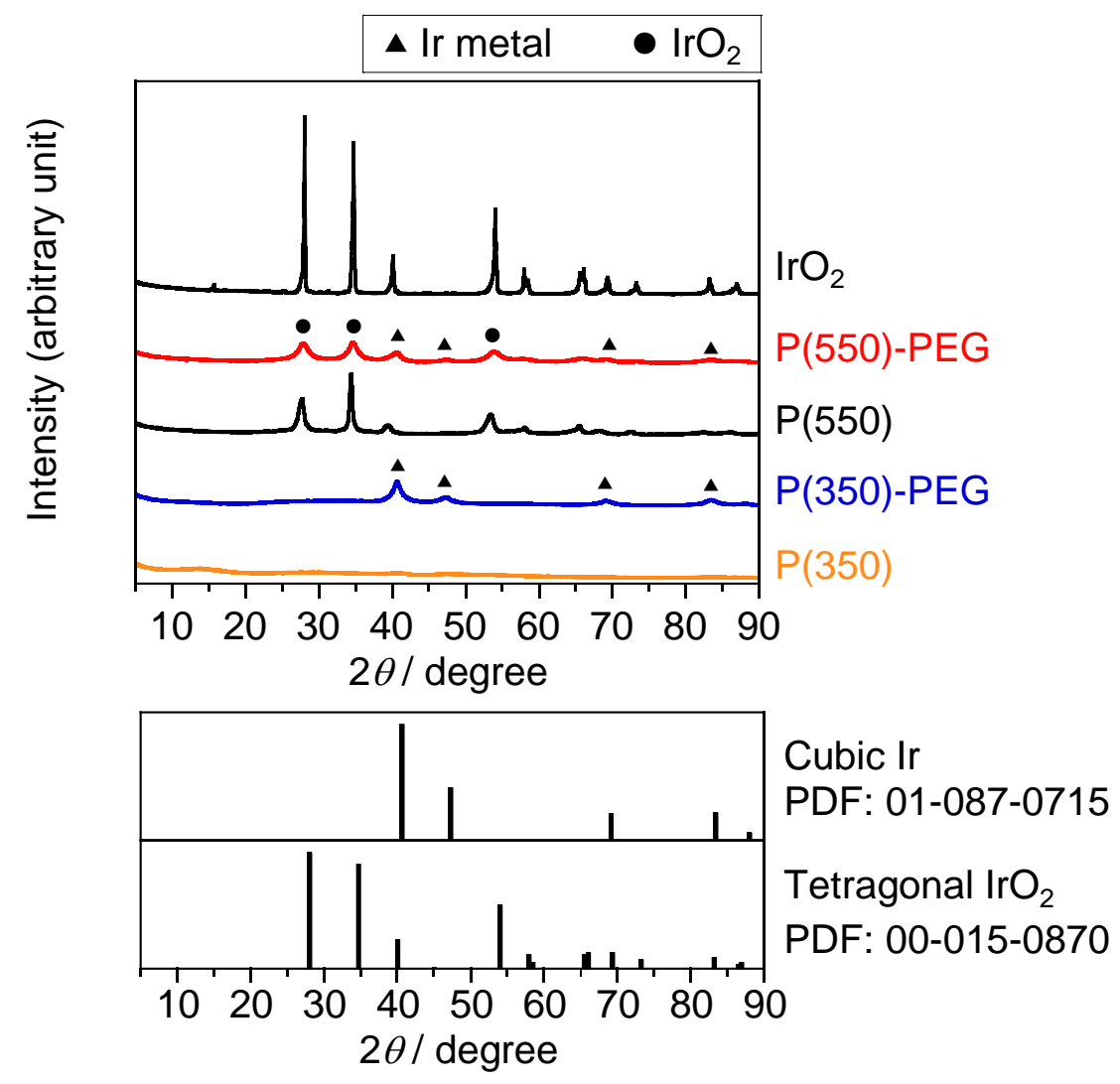

Figure S5. XRD patterns of $\mathrm{IrO}_{2}-\mathrm{Ta}_{2} \mathrm{O}_{5}$ powders and commercial $\mathrm{IrO}_{2}$ powder (Kojundo Chemical Laboratory). Powder diffraction file (PDF) of cubic $\operatorname{Ir}(01-087-0715)$ and tetragonal $\mathrm{IrO}_{2}$ (00-015-0870). 
(a)
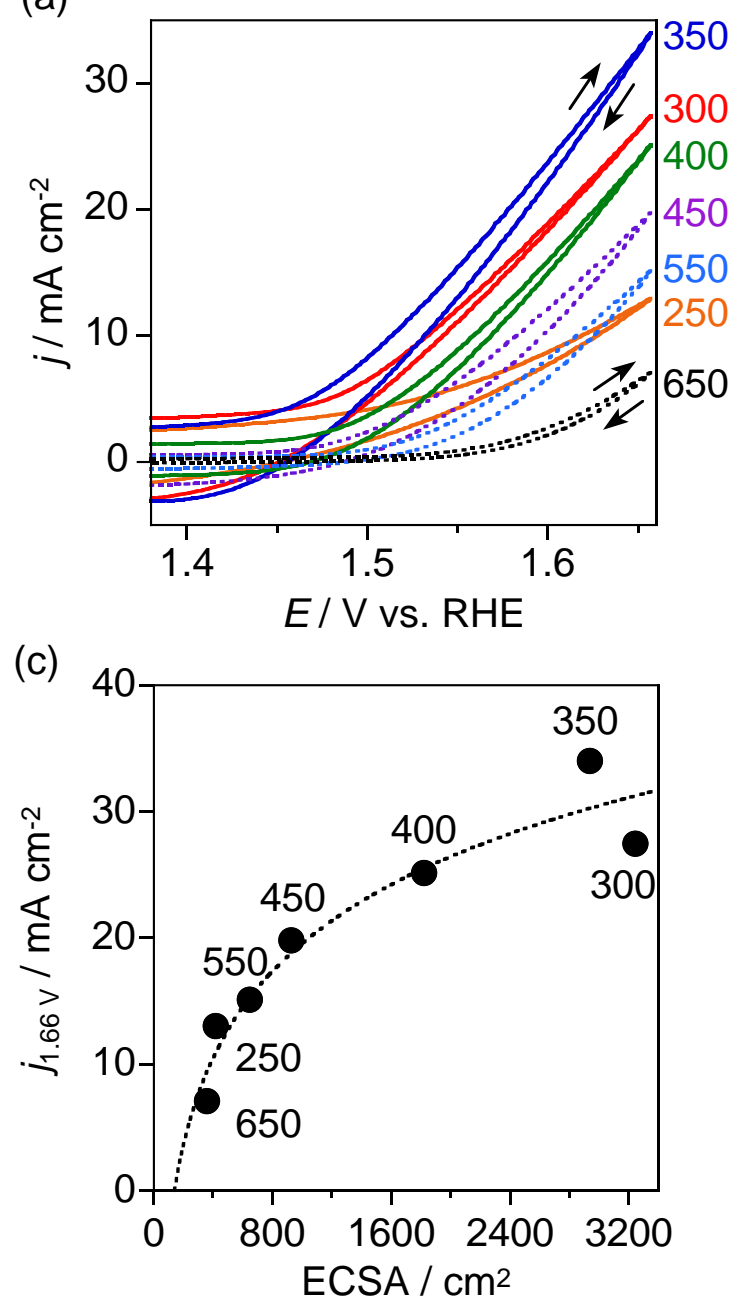

(b)

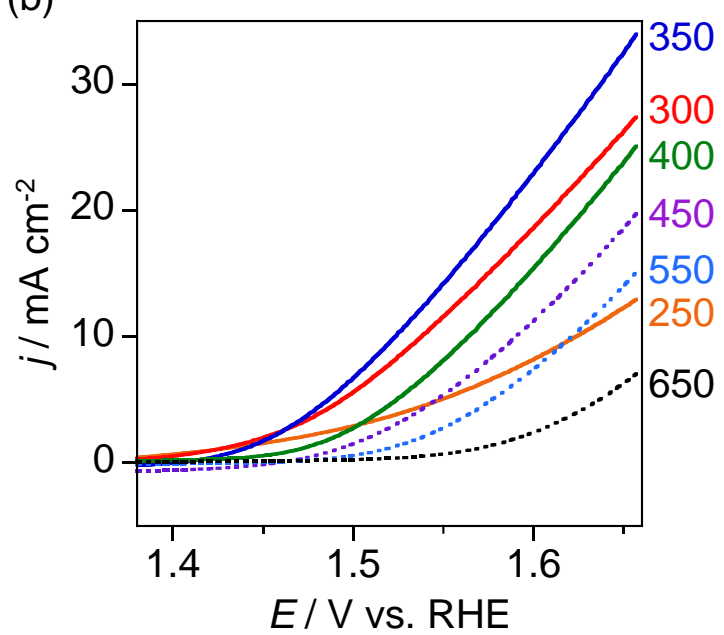

(d)

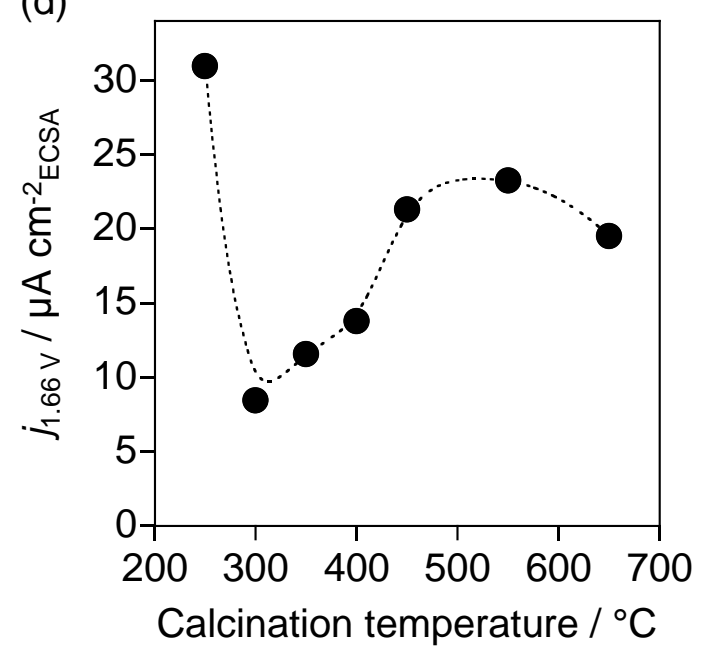

Figure S6. (a) Cyclic voltammograms at a scan rate of $20 \mathrm{mV} \mathrm{s}^{-1}$ for $\operatorname{IrO}_{2}-\mathrm{Ta}_{2} \mathrm{O}_{5} / \mathrm{Ti}$ felt $(x)-\mathrm{PEG}$ electrodes in $0.1 \mathrm{M} \mathrm{H}_{2} \mathrm{SO}_{4}(\mathrm{pH}=1)$. Sweep directions are shown by arrows. (b) Capacitancecorrected OER activities. The capacitance correction was performed by averaging forward and backward scans. (c) Relationship between ECSA and $j_{1.66 \mathrm{~V}}$. (d) ECSA-normalized $j_{1.66 \mathrm{~V}}$. 

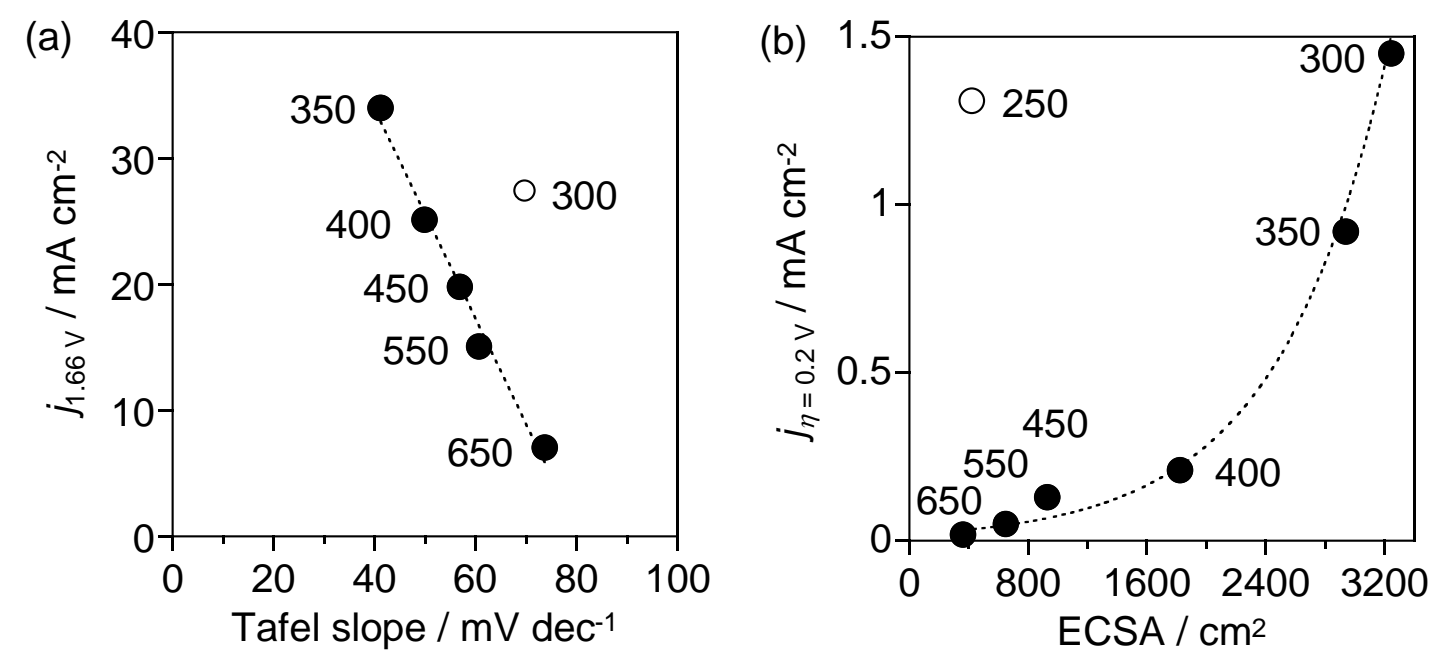

Figure S7. (a) Relationship between Tafel slope and $j_{1.66 \mathrm{~V}}$ and (b) relationship between ECSA and $j$ at $\eta=0.20 \mathrm{~V}\left(1.43 \mathrm{~V}\right.$ vs RHE) for $\mathrm{IrO}_{2}-\mathrm{Ta}_{2} \mathrm{O}_{5} / \mathrm{Ti}$ felt $(x)-\mathrm{PEG}$ electrodes in $0.1 \mathrm{M} \mathrm{H}_{2} \mathrm{SO}_{4}$ $(\mathrm{pH}=1)$. 
(a)
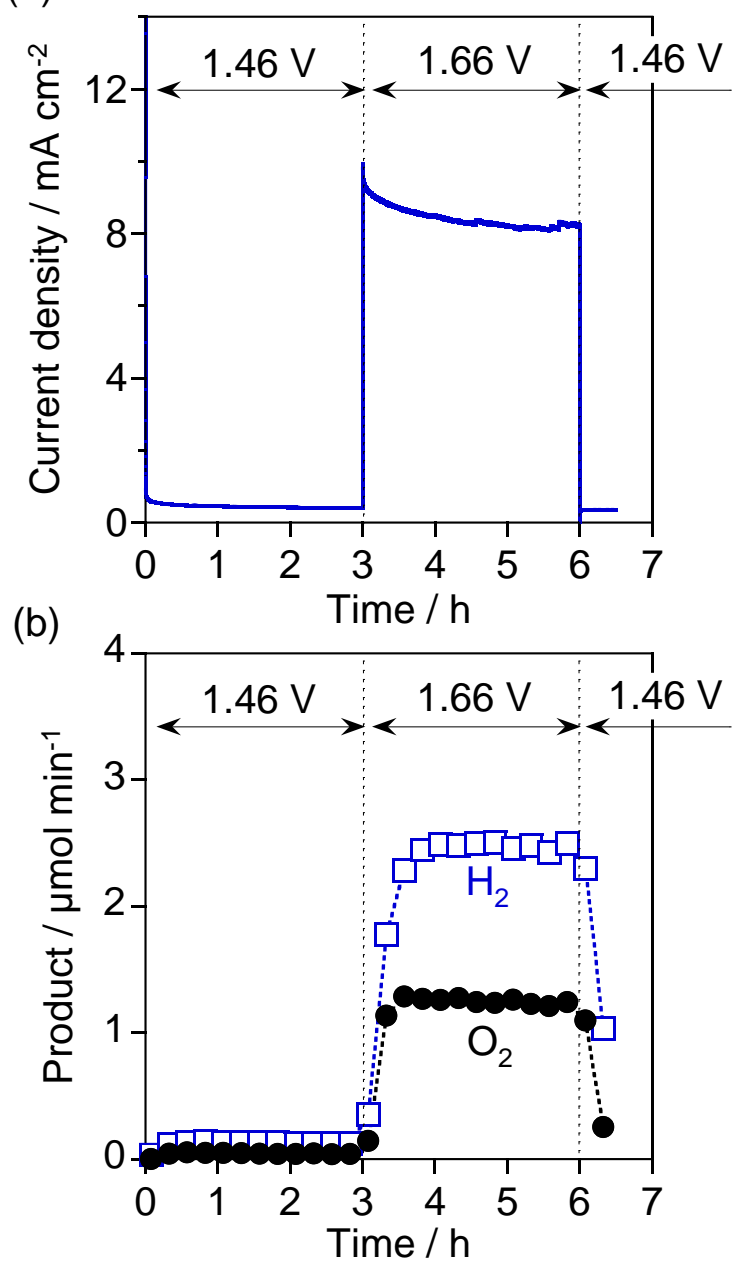

Figure S8. Water electrolysis of $0.1 \mathrm{M} \mathrm{H}_{2} \mathrm{SO}_{4}$ solution $(\mathrm{pH}=1)$ at $1.66 \mathrm{~V}$ vs. $\mathrm{RHE}$ and room temperature on $\mathrm{IrO}_{2}-\mathrm{Ta}_{2} \mathrm{O}_{5} / \mathrm{Ti}$ felt(350)-PEG anode. (a) Current density and (b) $\mathrm{H}_{2}$ formation rate in the platinum cathode compartment and $\mathrm{O}_{2}$ formation rate in the anode compartment. The two compartments were separated by a Nafion membrane. The gas phases were purged with Ar flows. The electrode potential was set to $1.46 \mathrm{~V}$ vs. RHE before and after the water electrolysis. The potential was not corrected for the ohmic drop. 


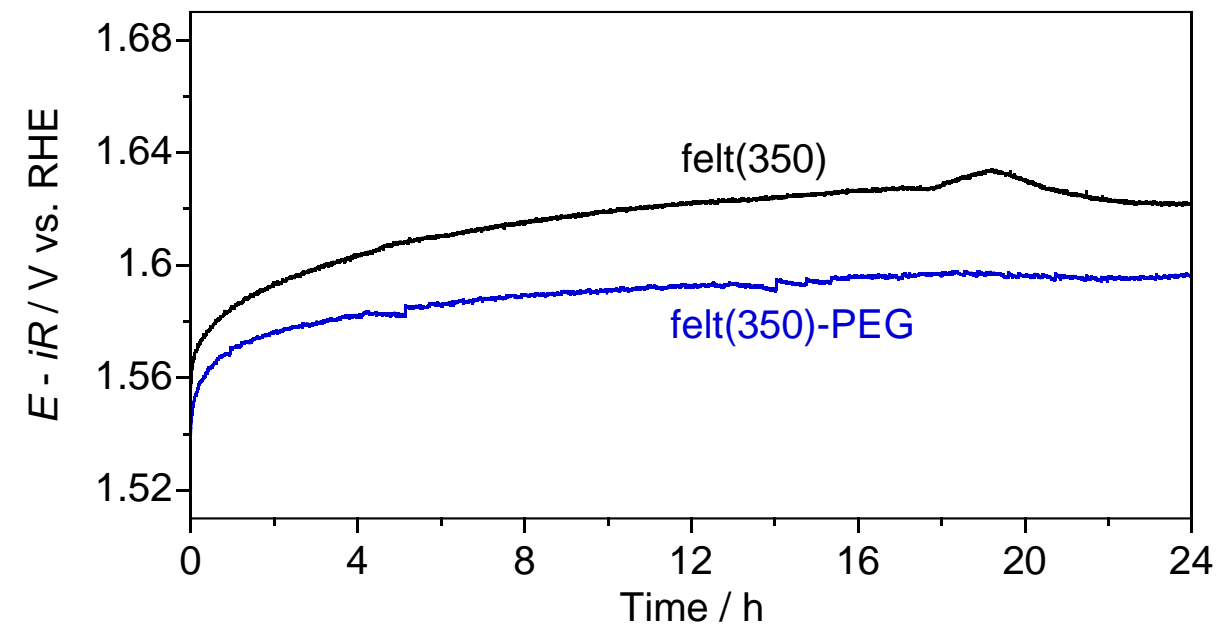

Fig S9. Stability test for $\mathrm{IrO}_{2}-\mathrm{Ta}_{2} \mathrm{O}_{5} / \mathrm{Ti}$ felt(350) and Felt(350)-PEG electrodes at $20 \mathrm{~mA} \mathrm{~cm}^{-2}$ in $0.1 \mathrm{M} \mathrm{H}_{2} \mathrm{SO}_{4}(\mathrm{pH}=1)$. The potentials were $i R$-corrected. 

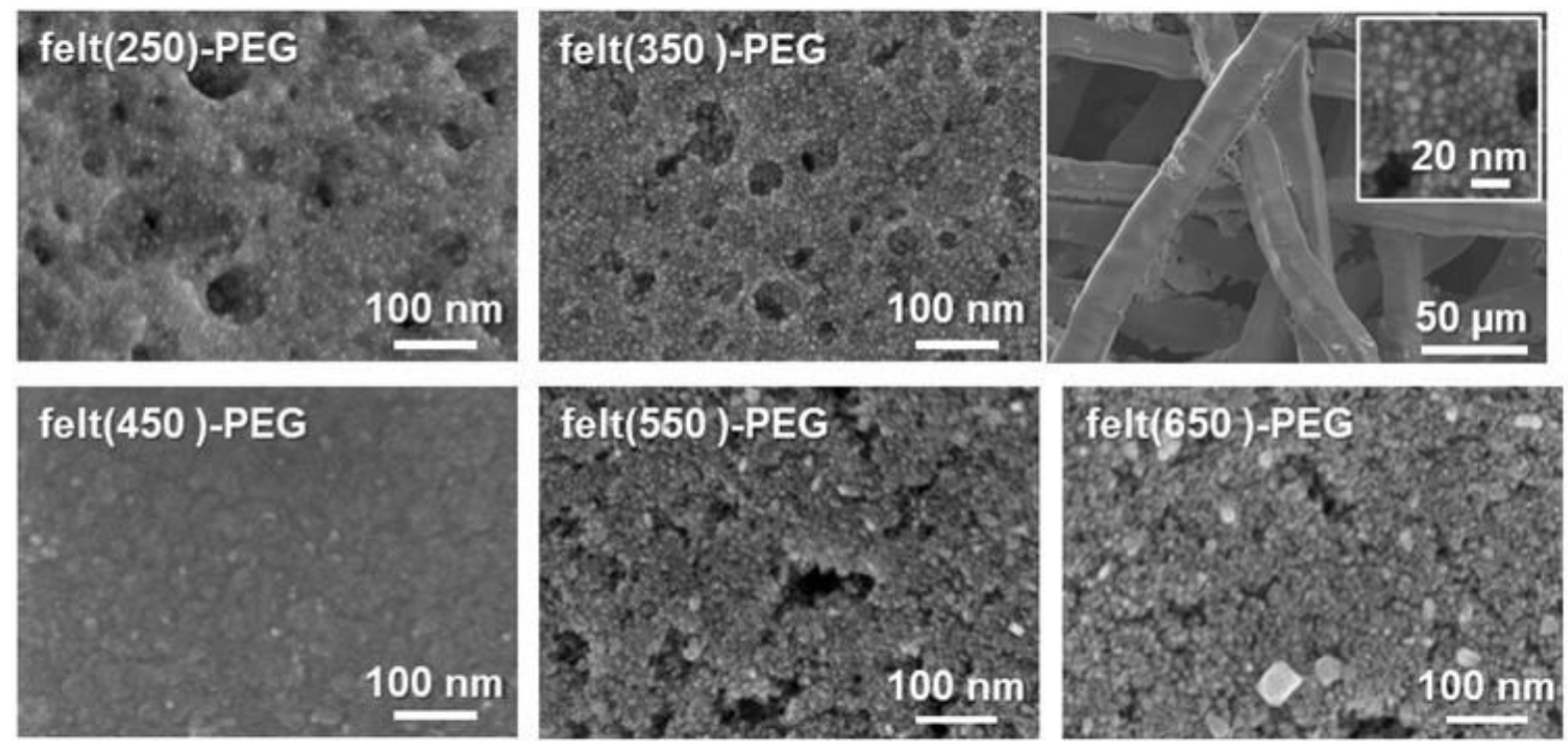

Figure S10. SEM images of $\mathrm{IrO}_{2}-\mathrm{Ta}_{2} \mathrm{O}_{5} / \mathrm{Ti}$ felt $(x)-\mathrm{PEG}$ electrodes prepared by different calcination temperatures. 
(a)

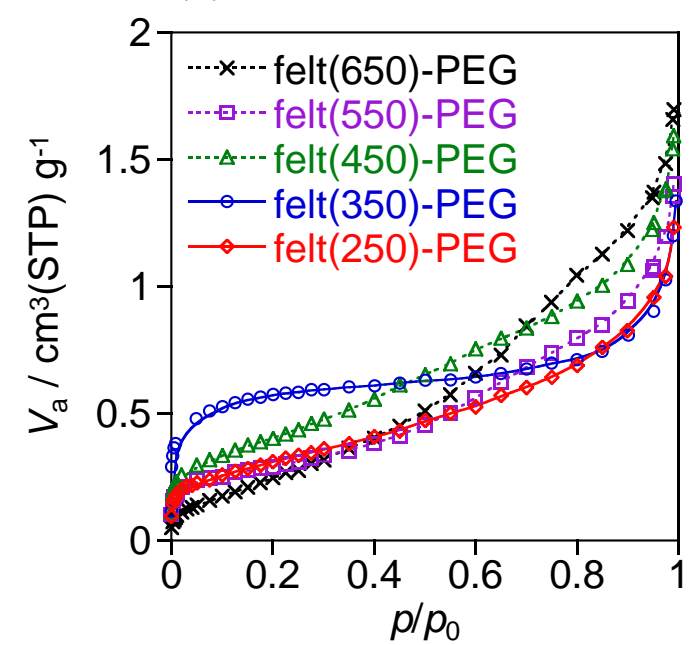

(c)

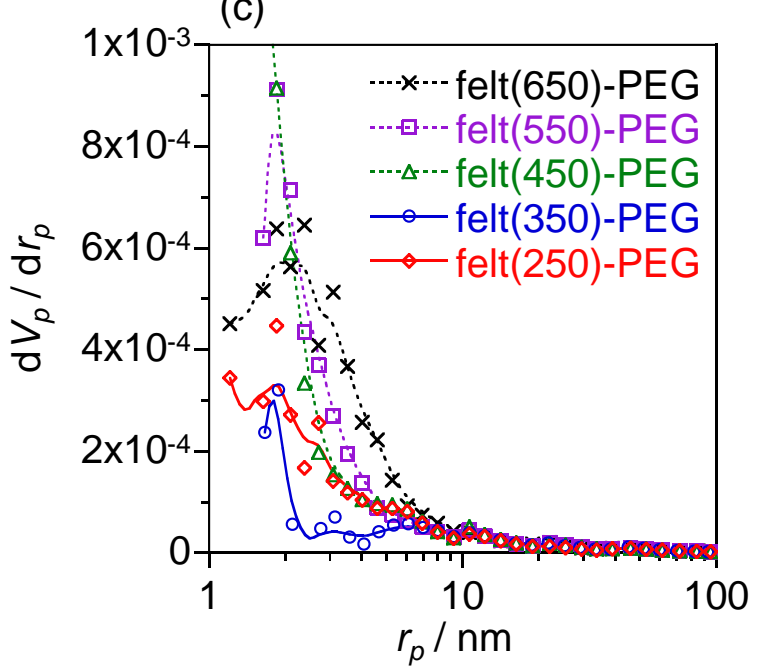

(b)

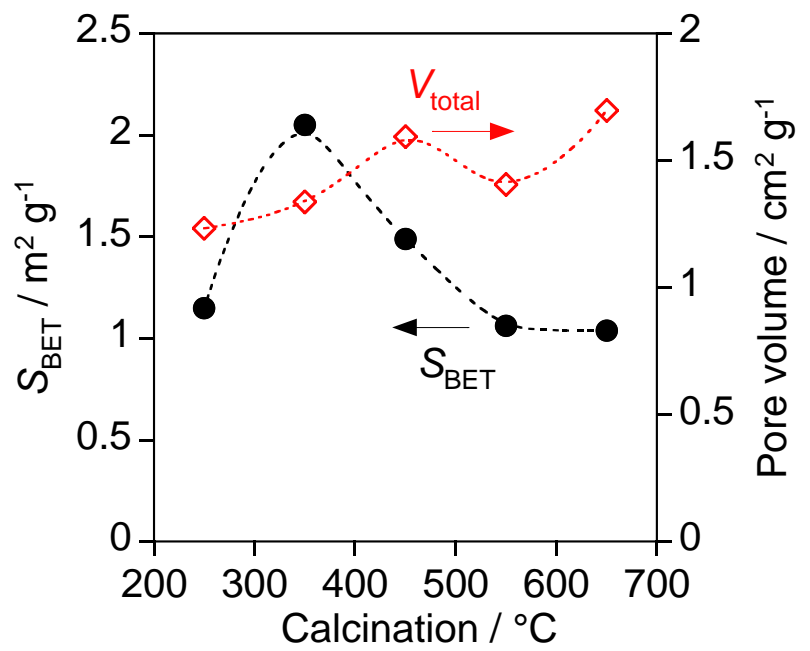

Figure S11. (a) Nitrogen adsorption isotherms, (b) BET specific surface area $\left(S_{\mathrm{BET}}\right)$ and total pore volume $\left(V_{\text {total }}\right)$, (c) pore size distributions calculated by the $\mathrm{BJH}$ method for $\mathrm{IrO}_{2}-\mathrm{Ta}_{2} \mathrm{O}_{5} / \mathrm{Ti}$ felt $(x)-$ PEG prepared by different calcination temperatures. The sample weight of $\mathrm{IrO}_{2}-\mathrm{Ta}_{2} \mathrm{O}_{5} / \mathrm{Ti}$ felt(350)-PEG was $550 \mathrm{mg}$, and the loading amount of $\mathrm{IrO}_{2}-\mathrm{Ta}_{2} \mathrm{O}_{5}$ layer was about $14 \mathrm{mg}$. The catalyst loading was about $2.5 \mathrm{wt} \%$. 

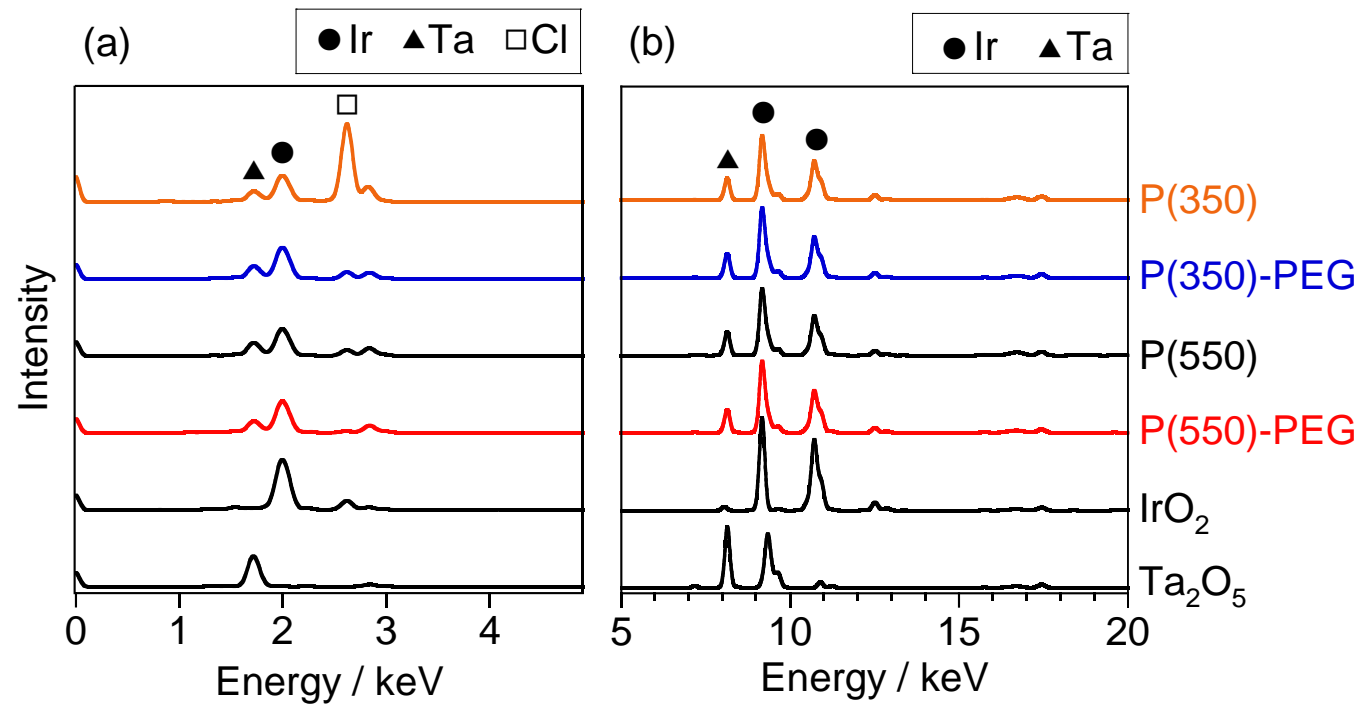

Figure S12. XRF spectra of $\mathrm{IrO}_{2}-\mathrm{Ta}_{2} \mathrm{O}_{5}, \mathrm{IrO}_{2}$, and $\mathrm{Ta}_{2} \mathrm{O}_{5}$ powders obtained with (a) $\mathrm{RX} 9$ and (b) Mo secondary targets. 

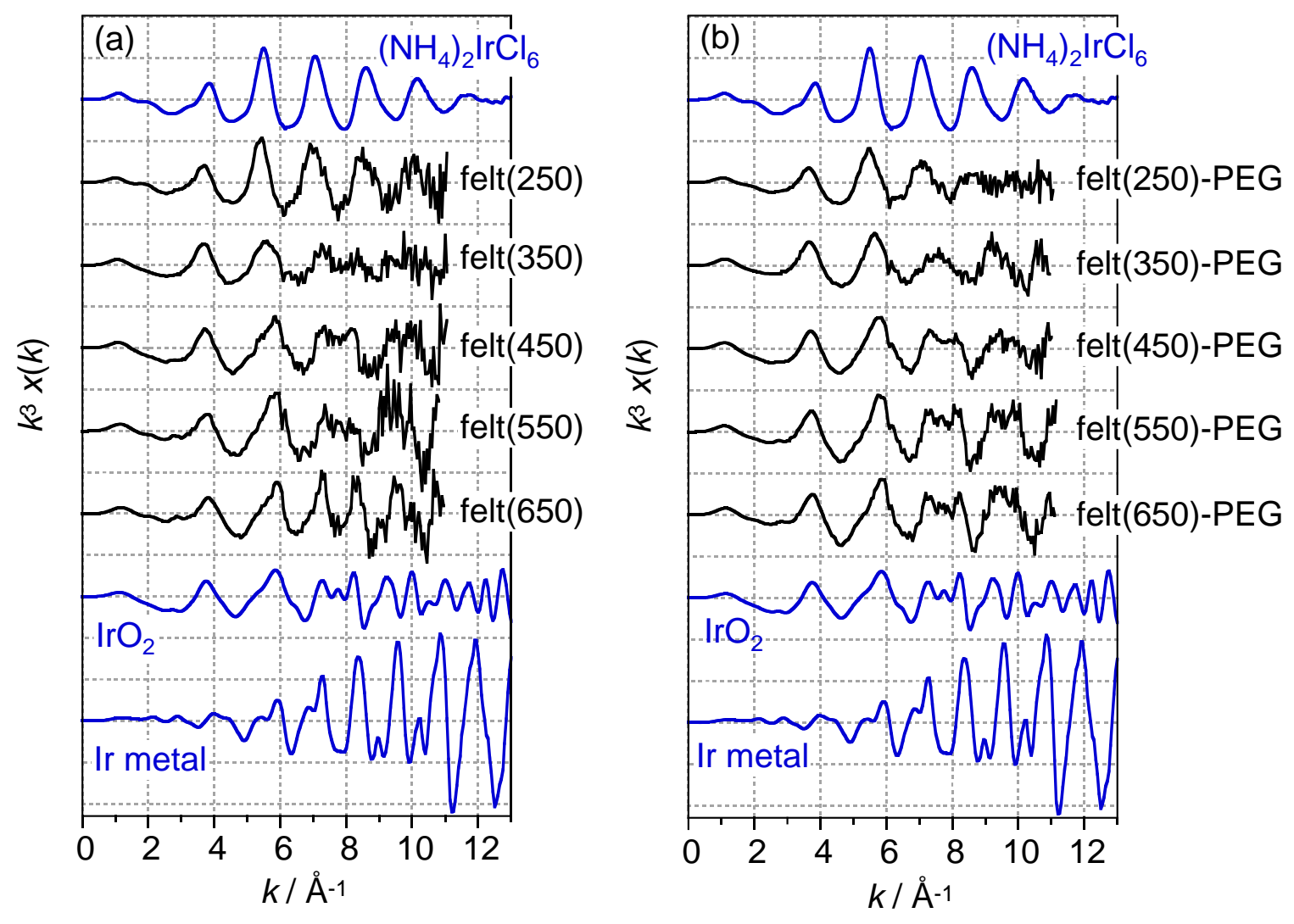

Figure S13. Ir $\mathrm{L}_{3}$-edge $k^{3}$-weighted EXAFS spectra of (a) $\operatorname{IrO}_{2}-\mathrm{Ta}_{2} \mathrm{O}_{5}(\mathrm{PEG}) / \mathrm{Ti}$ felt(y) and (b) $\mathrm{IrO}_{2}-\mathrm{Ta}_{2} \mathrm{O}_{5}(\mathrm{PEG} 50) / \mathrm{Ti}$ felt $(y)$. The references are $\left(\mathrm{NH}_{4}\right)_{2} \mathrm{IrCl}_{6}, \mathrm{IrO}_{2}$, and metallic Ir. 

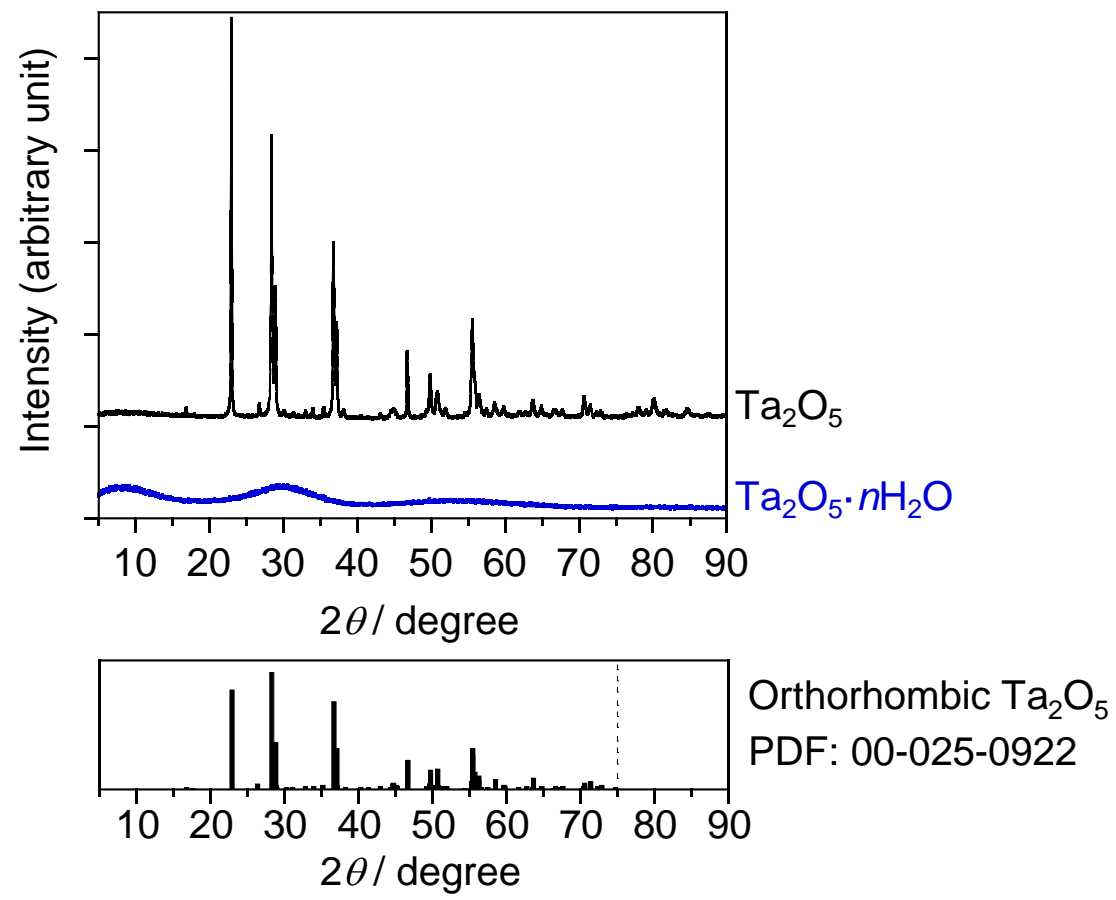

Figure S14. XRD patterns of $\mathrm{Ta}_{2} \mathrm{O}_{5}$ and $\mathrm{Ta}_{2} \mathrm{O}_{5} \cdot n \mathrm{H}_{2} \mathrm{O}$ powders. Powder diffraction file (PDF) of orthorhombic $\mathrm{Ta}_{2} \mathrm{O}_{5}$ (00-025-0922). 

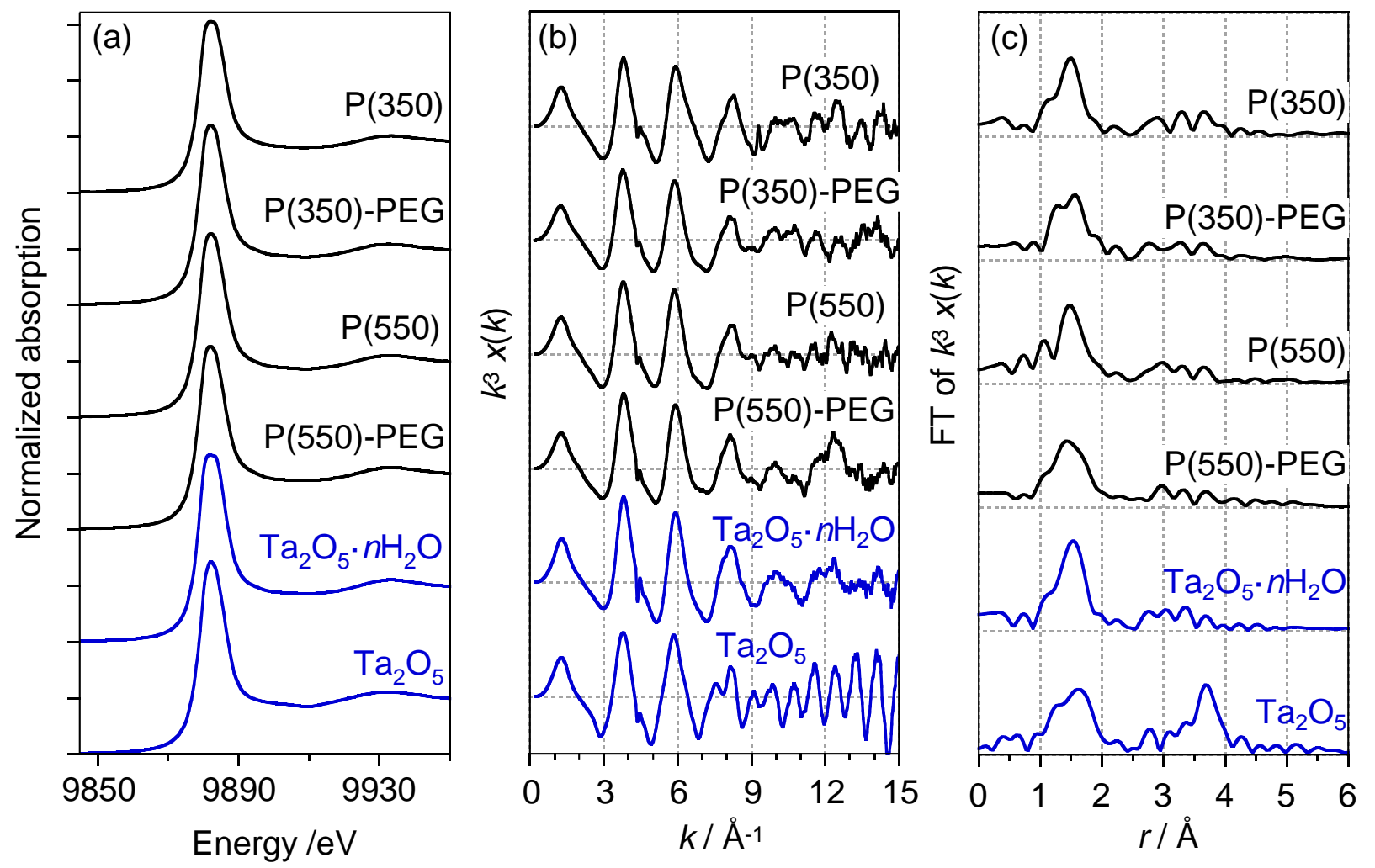

Figure S15. Ta L3-edge (a) XANES spectra, (b) $k^{3}$-weighted EXAFS spectra, and (c) FT-EXAFS spectra of $\operatorname{IrO}_{2}-\mathrm{Ta}_{2} \mathrm{O}_{5}$ powders: $\mathrm{P}(x)$ and $\mathrm{P}(x)-\mathrm{PEG}$. The reference samples are $\mathrm{Ta}_{2} \mathrm{O}_{5}$ and $\mathrm{Ta}_{2} \mathrm{O}_{5} \cdot n \mathrm{H}_{2} \mathrm{O}$ powders. 